Article

\title{
Quantitative Analysis, Extraction Optimization, and Biological Evaluation of Cudrania tricuspidata Leaf and Fruit Extracts
}

\author{
Seung-Hui Song ${ }^{1,+}$, Sung Hwan Ki ${ }^{2,+}$, Dae-Hun Park ${ }^{3}$, Hong-Seop Moon ${ }^{1}$, Chang-Dai Lee ${ }^{4}$, \\ In-Soo Yoon ${ }^{5, *}$ (iD and Seung-Sik Cho ${ }^{1, *}$ \\ 1 Department of Pharmacy, College of Pharmacy, Mokpo National University, Muan-gun, \\ Jeonnam 58554, Korea; tmdgm17898@naver.com (S.-H.S.); hbsmoon@mokpo.ac.kr (H.-S.M.) \\ 2 Laboratory of Toxicology, College of Pharmacy, Chosun University, Dong-gu, Gwangju 61452, Korea; \\ shki@chosun.ac.kr \\ 3 Department of Nursing, Dongshin University, Naju-si, Jeonnam 58245, Korea; dhj1221@hanmail.net \\ 4 Department of Business Administration, Mokpo National University, Muan-gun, Jeonnam 58554, Korea; \\ leecdai@mokpo.ac.kr \\ 5 Department of Manufacturing Pharmacy, College of Pharmacy, Pusan National University, \\ Geumjeong-gu, Busan 46241, Korea \\ * Correspondence: insoo.yoon@pusan.ac.kr (I.-S.Y.); sscho@mokpo.ac.kr (S.-S.C.); \\ Tel.: +82-51-510-2806 (I.-S.Y.); +82-61-450-2687 (S.-S.C.) \\ $\dagger$ These authors contributed equally to this work.
}

Received: 22 August 2017; Accepted: 5 September 2017; Published: 7 September 2017

\begin{abstract}
Cudrania tricuspidata Bureau (Moraceae) shows numerous pharmacological effects and has been used in traditional herbal remedies for inflammation, gastritis, tumors, and liver diseases. However, no validated analytical method for the standardization and optimization of the biological properties of $C$. tricuspidata preparations has been reported. We developed and validated a reverse-phase high-performance liquid chromatography (HPLC) method for the separation and quantification of active markers. Ethanolic extracts of $C$. tricuspidata leaves were prepared and evaluated for chemical profiles and biological activities. The $80 \%$ ethanolic extract demonstrated the greatest antioxidant activity and phenolic content, while the $100 \%$ ethanolic extract had the greatest total flavonoid content and xanthine oxidase $(\mathrm{XO})$ inhibitory activity. The validated HPLC method confirmed that chlorogenic acid, rutin, and kaempferol were present in C. tricuspidata leaf extracts. We postulated that the antioxidant and anti-hyperuricemic/gout effects of $C$. tricuspidata extract could be attributed to these marker compounds. Our results suggested that the flavonoid-rich fraction of the leaf extract may be utilized for the treatment and prevention of hyperuricemia-related diseases, and the validated method and marker compounds could be applied for the quality control of $C$. tricuspidata preparations.
\end{abstract}

Keywords: C. tricuspidata Bureau; simultaneous analysis; HPLC; xanthine oxidase; hyperuricemia

\section{Introduction}

Cudrania tricuspidata Bureau (Moraceae) is cultivated in South Korea and is used in traditional herbal remedies for inflammation, gastritis, tumors, and liver cell damage [1]. The usage of the leaf, fruit, and root of C. tricuspidata was reported in "Donguibogam", one of the classics in Eastern medicine, which is used as an essential reference for the study of traditional medicine in many countries, including South Korea, China, and Japan. C. tricuspidata is available throughout the year and is widely used as a folk remedy. The roots and leaves of this perennial herb contain pharmaceutically active substances with anti-cancer activity, antioxidant activity, and blood glucose-lowering effects. The root bark 
has demonstrated anti-atherosclerotic [2], anti-inflammatory [3], antioxidant [4], neuroprotective [5], hepatoprotective [6], and cytotoxic activity [7]. In addition, C. tricuspidata fruit is reported to have neuroprotective [8], anti-inflammatory [9,10], pancreatic lipase inhibitory [11], mast cell activating [12], monoamine oxidase inhibitory [13], and anti-obesity effects [14]. Additionally, a previous study reported that $C$. tricuspidata leaves inhibited lipase activity, reduced plasma triacylglycerol levels, and delayed lipid absorption in vivo [15].

The efficacy of various extracts and purified active components prepared using C. tricuspidata as a medical material has been studied extensively to date. The root bark, fruit, and leaf are the most commonly investigated (in decreasing order of the number of publications). The contents of single compounds identified in the root bark are insufficient for use as markers for pharmaceutical industrialization. Moreover, preparations involving the fruit or leaf could be better for productivity than those involving the root bark, as C. tricuspidata is a perennial plant (Table 1).

Table 1. Medicinal activity and composition of C. tricuspidata Bureau.

\begin{tabular}{|c|c|c|c|}
\hline Part & Usage & Material & Reference \\
\hline Leaf & Diabetes & Water extract & [15] \\
\hline Fruit & Anti-obesity & 6,8-Diprenylgenistein & [14] \\
\hline Fruit & Lipase inhibition & $\begin{array}{l}\text { Genistein, orobol, } 7,4^{\prime} \text {-dimethoxy-5-hydroxyisoflavone, genistin, oroboside } \\
3^{\prime} \text {-O-methylorobol-7-glucoside, sphaerobioside, wighteone, gancaonin A } 4^{\prime}, 5,7 \text {-trihydroxy } \\
\text { isoflavonone, 5,7,3, } 4^{\prime} \text {-tetrahydroxy-6-8-diprenylisoflavone, alpinumisoflavone, } \\
4^{\prime} \text {-O-methylalpinumisoflavone, } \\
5,3^{\prime}, 4^{\prime} \text {-trihydroxy- } 6^{\prime \prime}, 6^{\prime \prime} \text {-dimethylpyrano- }\left(2^{\prime \prime}, 3^{\prime \prime} ; 7,6\right) \text { isoflavone, Scandenone, derrone, } \\
\text { derrone- } 4^{\prime} \text {-O-methylether, isochandalone, ulexin B, ulexone } \mathrm{B},(+) \text {-dihydrokaempferol, } \\
\text { (+)-taxifolin, } \\
\text { (2R,3R)-7-( }(\beta \text {-glucopyranosyloxy)-2,3-dihydro-3,5-dihydroxy-2-(4-hydroxyphenyl) } \\
\text {-4H-1-benzopyran-4-one, astragalin, hirsutrin, populnin, nicotiflorin, rutin }\end{array}$ & [11] \\
\hline Fruit & Anti-allergy & $5,7,3^{\prime}, 4^{\prime}$-Tetrahydroxy-6,8-diprenylisoflavone & [12] \\
\hline Fruit & Dermatitis & Water extract (rutin) & [12] \\
\hline Fruit & Monoamine oxidase inhibition & Gancaonin A, 4'-O-methylalpinumisoflavone, alpinumisoflavone & [13] \\
\hline Root bark & Anti-athersclerotic & Catecholic xanthones & [2] \\
\hline Root bark & Anti-inflammatory & Cudratricusxanthone A & [3] \\
\hline Root bark & Antioxidant & $\begin{array}{l}\text { Cudranian } 1 \text {, cudranian } 2 \text {, kaempferol-7-O- } \beta \text {-D-glucopyranoside, } \\
\text { quercetin-7-O- } \beta \text {-D-glucopyranoside, aromadendrin }\end{array}$ & [4] \\
\hline Root bark & Neuroprotective & 5,7-Dihydroxychromone, demethylsuberosin, 3-O-methylcudraxanthone G & [5] \\
\hline
\end{tabular}

Few studies have been conducted on the leaves and fruits of $C$. tricuspidata, and the contents of pharmacologically active ingredients were insufficient for use as marker compounds for pharmaceutical industrialization. Considerable effort has been focused on developing C. tricuspidata as medicinal and functional food materials, but no positive results have been achieved. To the best of our knowledge, no validated analytical method for the standardization and optimization of biological properties of $C$. tricuspidata preparations has been reported in the literature.

We investigated the biological activities of extracts and their constituents obtained from C. tricuspidata leaves and fruits for the development of medicinal or functional food sources. In this study, leaf and fruit components were screened for the medicinal application of C. tricuspidata. Extracts of C. tricuspidata were prepared for the assessment of chemical composition and pharmacological properties. 


\section{Results and Discussion}

\subsection{Optimization of the Chromatographic Conditions}

The HPLC conditions were optimized in terms of mobile phase composition, column temperature, wavelength, and flow rate. A gradient program was used to separate the three active markers in a single run within a reasonable period. Detection wavelengths were set according to the UV absorption maxima of the compounds $(340 \mathrm{~nm})$. Under the proposed analytical conditions, a baseline resolution was obtained for all analytes. The chemical structures of active constituents identified and representative chromatograms of the standard mixture and sample extracts are shown in Figure 1.<smiles>O=C(/C=C/c1ccc(O)c(O)c1)O[C@@H]1C[C@@](O)(C(=O)O)C[C@H](O)[C@H]1O</smiles>

Chlorogenic acid<smiles>C[C@H]1O[C@H](OC[C@H]2O[C@H](Oc3c(-c4ccc(O)c(O)c4)oc4cc(O)cc(O)c4c3=O)[C@@H](O)[C@H](O)[C@H]2O)[C@H](O)[C@@H](O)[C@H]1O</smiles>

Rutin<smiles>O=c1c(O)c(-c2ccc(O)cc2)oc2cc(O)cc(O)c12</smiles>

Kaempferol

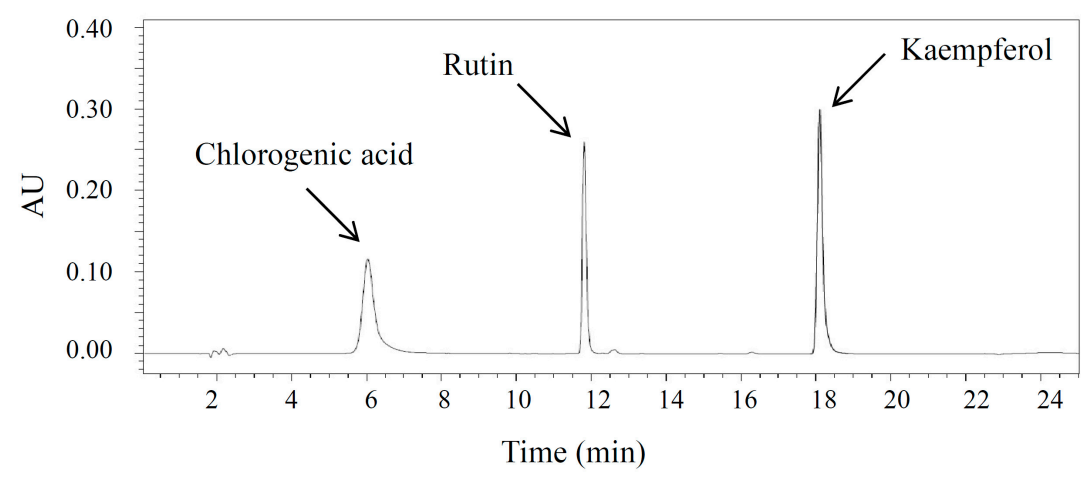

(B)

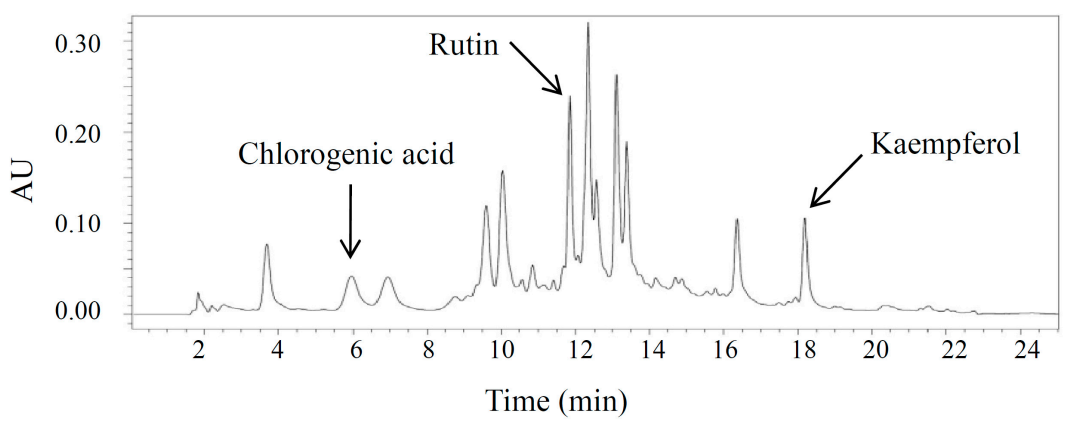

(C)

Figure 1. Cont. 


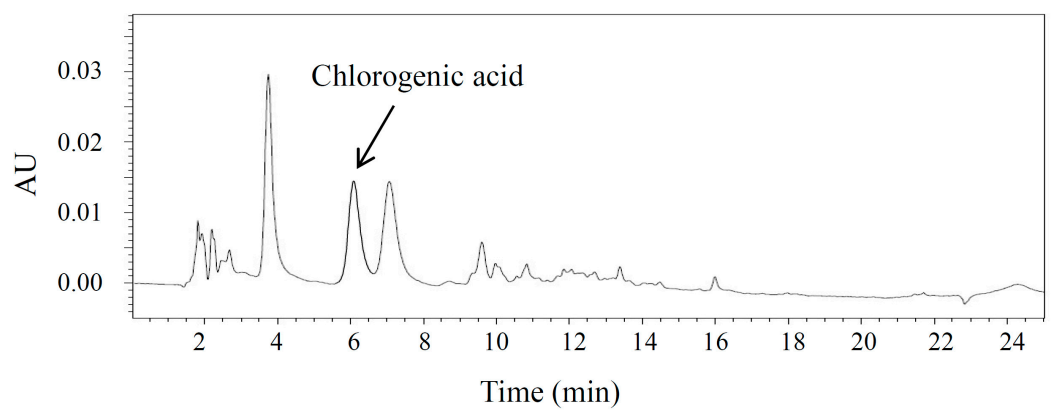

(D)

Figure 1. Identification of active compounds in C. tricuspidata leaf and fruit extracts by high-performance liquid chromatography (HPLC) analysis. (A) Chemical structures of chlorogenic acid, rutin, and kaempferol; (B) standard mixture at $340 \mathrm{~nm}$; (C) sample extract (leaf) at $340 \mathrm{~nm}$; (D) sample extract (fruit) at $340 \mathrm{~nm}$. A mobile phase consisting of a mixture of solvent A (acetonitrile) and B (water containing $0.2 \%$ phosphoric acid) and employing a gradient elution (from 10:90 to 100:0 $\mathrm{v} / \mathrm{v}$ ) was run at a flow rate of $0.8 \mathrm{~mL} / \mathrm{min}$.

\subsection{Method Validation}

\subsubsection{Limit of Detection (LOD) and Limit of Quantification (LOQ)}

The limit of detection (LOD) of an individual analytical procedure is the lowest amount of an analyte in a sample that can be detected but not necessarily quantified. The LOD was $0.88,0.32$ and $0.05 \mu \mathrm{g} / \mathrm{mL}$ for chlorogenic acid, rutin, and kaempferol, respectively (Table 1). The limit of quantification (LOQ) of an individual analytical procedure is the lowest amount of analyte in a sample that can be quantified with suitable precision and accuracy. The LOQ was $6.25 \mu \mathrm{g} / \mathrm{mL}$, which is the lowest level in the linear concentration range with acceptable precision and accuracy (Table 1).

\subsubsection{Linearity}

Calibration curves were linear over a concentration range of $6.25-100 \mu \mathrm{g} / \mathrm{mL}$ for the three markers. The calibration curves exhibited good linear regressions $\left(r^{2}>0.999\right.$ for chlorogenic acid, rutin, and kaempferol; Table 2).

Table 2. High-performance liquid chromatography (HPLC) data for the calibration graphs and limit of quantification (LOQ) of the three active compounds.

\begin{tabular}{cccccc}
\hline Analyte & Retention Time $(\mathbf{m i n})$ & $\boldsymbol{R}^{\mathbf{2}}$ & Linear Range $(\boldsymbol{\mu g} / \mathrm{mL})$ & LOQ $(\mu \mathrm{g} / \mathrm{mL})$ & LOD $(\boldsymbol{\mu g} / \mathbf{m L})$ \\
\hline Chlorogenic acid & 6.0 & 0.9999 & $6.25-100$ & 6.25 & 0.88 \\
Rutin & 11.8 & 0.9999 & $6.25-100$ & 6.25 & 0.32 \\
Kaempferol & 18.1 & 0.9999 & $6.25-100$ & 6.25 & 0.05 \\
\hline
\end{tabular}

\subsubsection{Precision and Accuracy}

The results of the intraday and interday precision experiments are shown in Table 3. The developed method was precise, as indicated by relative standard deviation (RSD) values $(<2.5 \%)$ for the repeatability of the intraday and interday precision studies, which were below the limit recommended by the International Conference on Harmonisation (ICH) guidelines [16]. The overall recovery percentages were in the range of $99.2-106.9 \%$ for chlorogenic acid, 103.6-108.3\% for rutin and $103.7-107.7 \%$ for kaempferol. These results demonstrate that the developed method is reproducible with good accuracy (Table 3). 
Table 3. Analytical results of intraday and interday precision and accuracy.

\begin{tabular}{cccccc}
\hline \multirow{2}{*}{ Analyte } & \multirow{2}{*}{ Conc. $(\mu \mathrm{g} / \mathrm{mL})$} & \multicolumn{2}{c}{ Intraday $(\boldsymbol{n}=\mathbf{3})$} & \multicolumn{2}{c}{ Interday $(\boldsymbol{n}=\mathbf{3})$} \\
\cline { 3 - 6 } & & RSD (\%) $^{\mathbf{a}}$ & Accuracy (\%) & RSD (\%) & Accuracy (\%) \\
\hline \multirow{3}{*}{ Chlorogenic acid } & 12.5 & 1.7 & 105.6 & 6.1 & 102.6 \\
& 25 & 3.4 & 106.9 & 4.0 & 99.2 \\
& 50 & 0.3 & 106.2 & 4.1 & 102.5 \\
\hline \multirow{3}{*}{ Rutin } & 12.5 & 0.5 & 106.6 & 2.8 & 108.3 \\
& 25 & 1.3 & 103.6 & 2.3 & 105.3 \\
& 50 & 0.2 & 107.1 & 1.0 & 107.0 \\
\hline \multirow{3}{*}{ Kaempferol } & 12.5 & 2.8 & 107.6 & 3.0 & 107.7 \\
& 25 & 2.5 & 103.7 & 2.4 & 104.3 \\
& 50 & 1.0 & 107.2 & 1.0 & 106.0 \\
\hline
\end{tabular}

a RSD: relative standard deviation.

\subsubsection{Repeatability}

The results of the repeatability experiments are shown in Table 4. The developed method was precise; the RSD values for the repeatability precision studies were below $2.0 \%$.

Table 4. Analytical data of recovery $(n=6)$.

\begin{tabular}{cccc}
\hline Analyte & Added $(\mu \mathrm{g} / \mathbf{m L})$ & Recovery $(\% ;$ mean \pm SD) & RSD (\%) ${ }^{\mathbf{a}}$ \\
\hline \multirow{3}{*}{ Chlorogenic acid } & 12.5 & $103.6 \pm 1.7$ & 1.7 \\
& 25 & $101.0 \pm 1.6$ & 1.6 \\
& 50 & $101.4 \pm 1.4$ & 1.4 \\
\hline \multirow{3}{*}{ Rutin } & 12.5 & $104.0 \pm 1.6$ & 1.5 \\
& 25 & $99.2 \pm 0.1$ & 0.1 \\
Kaempferol & 50 & $101.4 \pm 0.6$ & 0.6 \\
& 12.5 & $104.4 \pm 1.2$ & 1.2 \\
& 25 & $99.2 \pm 0.2$ & 0.2 \\
\hline
\end{tabular}

a $\mathrm{RSD}$ : relative standard deviation.

\subsection{Contents of Marker Compounds from C. tricuspidata Extracts}

Plant samples were extracted with six different solvent compositions to select the best extraction solvent conditions: water, $20 \%$ ethanol, $40 \%$ ethanol, $60 \%$ ethanol, $80 \%$ ethanol, and $100 \%$ ethanol $(v / v)$. The validated HPLC method was applied to analyze the six extracts. The average amounts (wt \%) of chlorogenic acid and rutin are presented in Figure 2. The contents of the two compounds in the $80 \%$ ethanolic extract were greater than those in the other ethanolic extracts. On the basis of these results, the $80 \%$ ethanol was selected as the most effective extraction solvent.

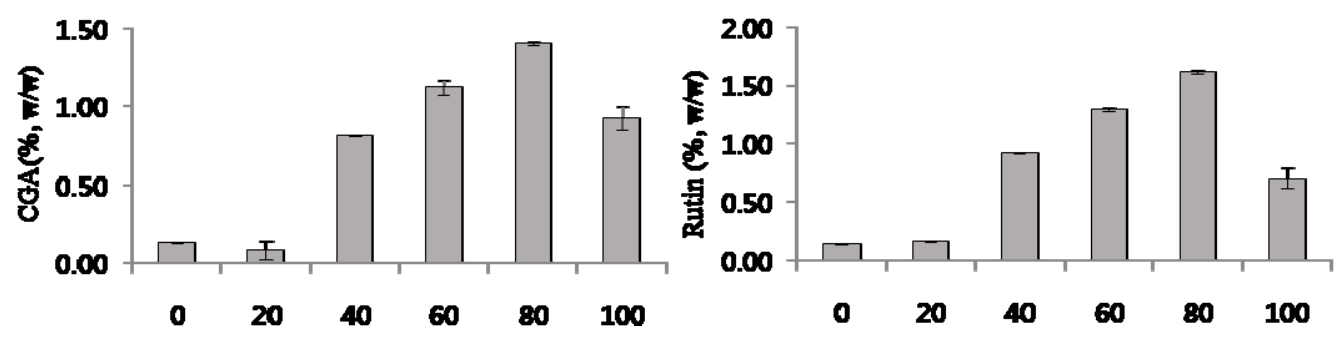

Figure 2. Content of chlorogenic acid (CGA) and rutin in ethanolic extracts from $C$. tricuspidata leaves; $0-100$ on $x$-axis: $0-100 \%$ ethanolic extract. Each value was the mean $\pm \operatorname{SD}(n=3)$. 


\subsection{Antioxidant Activity, Total Phenolic Contents, and Total Flavonoids of C. tricuspidata Extracts}

The antioxidant potential of various extracts of $C$. tricuspidata was determined by the 2,2-diphenyl-1-picrylhydrazyl (DPPH) and reducing power assays. Plants are rich sources of phytochemicals with antioxidant activity [16]. Antioxidative properties of plant preparations were correlated with the major active constituents' contents, such as polyphenols and flavonoids. Therefore, we determined the total phenolic contents and flavonoids of various extracts obtained from C. tricuspidata.

DPPH analysis is a common method for evaluating the free radical scavenging ability of plant extracts. The measured DPPH radical scavenging activity is shown in Figure 3. The antioxidant activity of DPPH radicals decreased in the following order: $80 \%$ ethanol extract $(72.3 \pm 0.7 \%)>60 \%$ ethanol extract $(66.8 \pm 1.1 \%)>$ hot water extract $(65.1 \pm 0.9 \%)>40 \%$ ethanol extract $(60.1 \pm 0.9 \%)>100 \%$ ethanol extract $(52.4 \pm 0.9 \%)>20 \%$ ethanol extract $(48.7 \pm 0.9 \%)$.

$\mathrm{Fe}^{3+}$ was reduced to $\mathrm{Fe}^{2+}$ in the presence of extracts to measure the reductive capability. The $80 \%$ ethanolic extract had the highest activity among the six extracts. The reductive activity, which was expressed as vitamin C equivalents, decreased in the following order: $80 \%$ ethanol extract $(28.3 \pm 0.5 \mu \mathrm{g} / \mathrm{mL})>60 \%$ ethanol extract $(27.5 \pm 0.3 \mu \mathrm{g} / \mathrm{mL})>40 \%$ ethanol extract $(26.7 \pm 0.3 \mu \mathrm{g} / \mathrm{mL})$ $>$ water extract $(26.3 \pm 0.6 \mu \mathrm{g} / \mathrm{mL})>100 \%$ ethanol extract $(25.8 \pm 0.3 \mu \mathrm{g} / \mathrm{mL})>20 \%$ ethanol extract $(24.9 \pm 0.6 \mu \mathrm{g} / \mathrm{mL})$.

The total phenolic content was determined by the Folin-Ciocalteu method [16] and was reported as gallic acid equivalents by reference to the standard curve $\left(r^{2}>0.999\right)$, as shown in Table 5 . The phenolic content in the $80 \%$ ethanolic extract was higher than that in the other ethanolic extracts. The $80 \%$ ethanolic extract showed the highest DPPH radical scavenging activity, reducing power, and phenolic content.

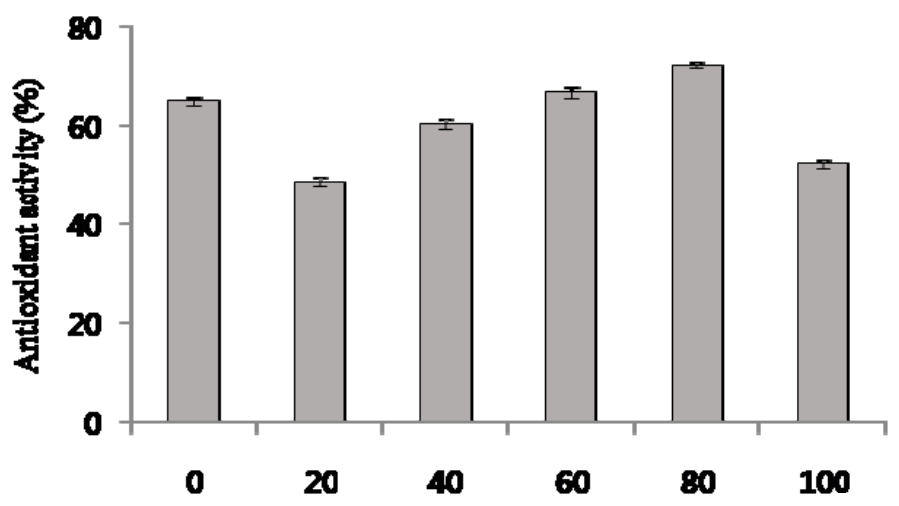

Figure 3. 2,2-Diphenyl-1-picrylhydrazyl (DPPH) scavenging effect in ethanolic extracts from $C$. tricuspidata leaves. $0-100$ on $x$-axis: $0-100 \%$ ethanolic extract. Each value was the mean $\pm \operatorname{SD}(n=3)$.

Table 5. Antioxidant activity and total phenolic content of C. tricuspidata leaf extracts.

\begin{tabular}{ccc}
\hline Extract & Reducing Power (Ascorbic Acid Eq. $\boldsymbol{\mu g} / \mathbf{1 0 0} \boldsymbol{\mu g}$ Extract) & Total Phenolic Content (Gallic Acid Eq. $\mathbf{~ m g / g )}$ \\
\hline Water & $26.3 \pm 0.6$ & $85.6 \pm 0.9$ \\
$20 \%$ EtOH Ex & $24.9 \pm 0.6$ & $81.3 \pm 1.4$ \\
$40 \%$ EtOH Ex & $26.7 \pm 0.3$ & $86.9 \pm 2.1$ \\
$60 \%$ EtOH Ex & $27.5 \pm 0.3$ & $93.2 \pm 2.4$ \\
$80 \%$ EtOH Ex & $28.3 \pm 0.5$ & $99.2 \pm 1.2$ \\
$100 \%$ EtOH Ex & $25.8 \pm 0.3$ & $92.8 \pm 4.1$ \\
\hline
\end{tabular}

These results suggest that solvent combinations may affect the phenolic extraction process. In our case, $80 \%$ ethanol was the most efficient solvent system for the extraction of phenolic compounds from $C$. tricuspidata. From the ethanolic extracts of $C$. tricuspidata leaves, we identified chlorogenic acid, 
rutin, and kaempferol. These antioxidant phenolic compounds are often found in medicinal plants and functional food sources [17-19].

The total flavonoid content was determined by an aluminum chloride assay [20] and was reported as quercetin equivalents by reference to a standard curve $\left(r^{2}>0.999\right)$, as shown in Figure 4 . The flavonoid content in the $100 \%$ ethanolic extract was greater than that in the other ethanolic extracts. All flavonoids are phenolic compounds, but not all phenolic compounds are necessarily flavonoids. The total phenolic content in the $100 \%$ ethanolic extract was $92.8 \pm 4.1 \mathrm{mg} / \mathrm{g}$ gallic acid equivalents (Table 5), and total flavonoids were $87.7 \pm 3.1 \mathrm{mg} / \mathrm{g}(8.8 \% \mathrm{w} / \mathrm{w})$ quercetin equivalents. These results indicate that the $100 \%$ ethanolic extract was the flavonoid-rich fraction. There is evidence that flavonoid-rich extracts from plant sources can exert various pharmacological effects in vitro and in vivo. Citraro et al. reported that a flavonoid-rich extract from orange juice possesses antiepileptic effects for pentylenetetrazol (PTZ)-induced seizures and in GS-sensible DBA/2 (Dilute Brown Non-Agouti) mice [21]. Huang et al. reported hypoglycemic activity and potential mechanisms of a flavonoid-rich ethyl acetate extract from Sophora tonkinensis Gagnep. in KK-Ay diabetic mice (type 2 diabetes) and identified 13 flavonoids [22]. However, a quantitative analysis of the flavonoid content was not performed in these previous studies. Peng et al. prepared a flavonoid-rich extract from Maydis stigma using a two-step extraction, and found the total flavonoid content to be $10.45 \%$ $(w / w)$. They reported the acute toxicity, safety, and antioxidant activity of the flavonoid-rich extract in mice [23]. Gajaria et al. reported that an extract from Murraya koenigii alleviated in vitro low-density lipoprotein (LDL) oxidation, which induced apoptosis in murine macrophage cells [24]. In the study, leaves of M. koenigii were defatted overnight with $70 \%$ petroleum ether and extracted with $80 \%$ methanol. The total flavonoid content of the extract was found to be $3.1 \pm 0.5 \mathrm{mg} / \mathrm{g}(0.3 \% w / w)$ [24]. Liu et al. reported that a flavonoid-rich extract from Rosa laevigata fruit shows biological effects against $\mathrm{H}_{2} \mathrm{O}_{2}$-induced oxidative injury in PC12 cells by adjusting oxidative stress, and suppresses apoptosis and inflammation [25]. They identified three flavonoids as key compounds in the extract, and their contents were determined to be $3.11 \%, 2.72 \%$, and $1.49 \%$, respectively [25]. The total flavonoid content of $C$. tricuspidata extracts prepared in our present study was $8.8 \%$, which was much higher than that of M. koenigii as reported by Gajaria et al. [24]. and which was similar to that of M. stigma as reported by Peng et al. [23].

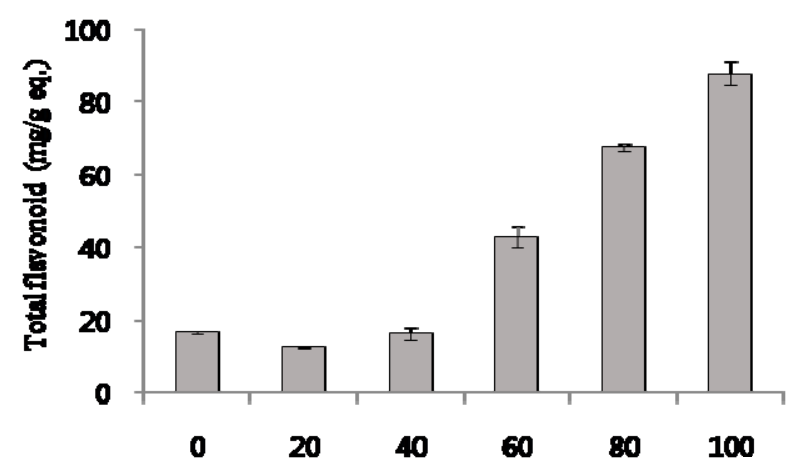

Figure 4. Total flavonoid content of ethanolic extract from C. tricuspidata leaves; 0-100 on $x$-axis: $0-100 \%$ ethanolic extract. Each value was the mean $\pm \operatorname{SD}(n=3)$.

\subsection{Xanthine Oxidase Inhibitory Activity of C. tricuspidata Extracts}

Figure 5 shows the effect of ethanol concentration on the xanthine oxidase $(\mathrm{XO})$ inhibitory activity of C. tricuspidata leaf ethanolic extracts. Figure 5 shows that allopurinol (ALP; positive control) at a concentration of $50 \mu \mathrm{g} / \mathrm{mL}$ significantly inhibited XO activity $(98.7 \pm 0.05 \%)$. The XO inhibitory activity of the ethanolic extracts significantly increased by increasing the ethanol concentration from 0 to $100 \%$ $(75.4 \pm 0.9 \%)$. 
Previously, we had screened various medicinal sources for XO inhibitory activity. Among 229 medicinal plant extracts, 3 extracts were selected as potential XO inhibitors [26]. Extracts from Corylopsis coreana and Camellia japonica inhibited the $X \mathrm{O}$ at a concentration of $2 \mathrm{mg} / \mathrm{mL}$, and relative inhibiton levels were $50 \%$ to $60 \%$ [20,27]. The extract from Quercus acuta inhibited the XO at a concentration of $1 \mathrm{mg} / \mathrm{mL}$, and the inhibition level was $~ 50 \%$ [26]. The plant extracts with XO inhibitory activity in the range of $1-2 \mathrm{mg} / \mathrm{mL}$ demonstrated consistent effects in the in vivo animal disease model. We posit that $100 \%$ ethanolic extract of C. tricuspidata leaves can be developed as a candidate for anti-hyperuricemic and anti-gout medicine.

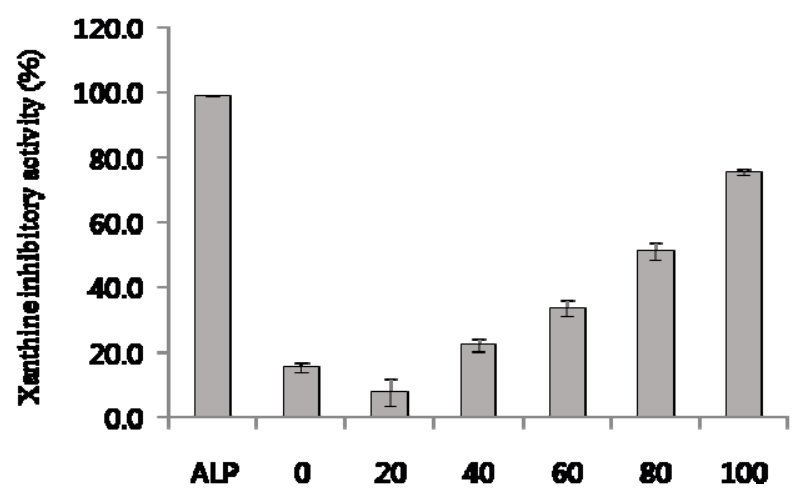

Figure 5. Xanthine oxidase (XO) inhibitory activites of ethanolic extract from $C$. tricuspidata leaves. ALP: allopurinol (50 $\mu \mathrm{g} / \mathrm{mL}) ; 0-100$ on $x$-axis: $0-100 \%$ ethanolic extract $(2 \mathrm{mg} / \mathrm{mL}$ ). Each value was the mean $\pm \operatorname{SD}(n=3)$.

We identified chlorogenic acid, rutin, and kaempferol as marker compounds from the ethanolic extracts of $C$. tricuspidata leaves. Rutin is a flavonoid known to have various pharmacological activities, such as antioxidant, anti-convulsant, anti-inflammatory, anti-Alzheimer, and anti-hyperuricemia activities [27-30]. A previous study reported that rutin at doses of $50-100 \mathrm{mg} / \mathrm{kg}$ significantly reduced the levels of biomarkers such as serum urate, creatinine, blood urea nitrogen, and serum/kidney uromodulin in hyperuricemic mice [29]. In another study, rutin demonstrated dose-dependent hypouricemic effects by inhibiting xanthine dehydrogenase/xanthine oxidase $(\mathrm{XDH} / \mathrm{XO})$ activity [30]. Chlorogenic acid is a phenolic compound with various pharmacological effects, such as antioxidant, anti-inflammatory, anti-allergy, and anti-hyperuricemia effects [17,31-34]. Meng et al. reported that chlorogenic acid significantly reduced the Sur level by inhibiting XO activity without increasing the urinary uric acid level [32]. Chlorogenic acid also alleviates the symptoms of inflammation induced by uric acid crystals by inhibiting the production of proinflammatory cytokines, including interleukin-1 $\beta$ (IL-1 $\beta$ ), interleukin-6 (IL-6), and tumor necrosis factor- $\alpha$ (TNF- $\alpha$ ) [32-34]. These results suggest that chlorogenic acid may have considerable potential for development as an anti-gouty arthritis agent. Kaempferol is a flavonoid with antioxidant, antimicrobial, anti-inflammatory, anti-ulcer and XO inhibitory activities [18,35-37]. Nagao et al. reported that kaempferol inhibited XO activity at low concentrations in a mixed-type mode, suggesting that certain flavonoids might suppress the formation of active oxygen species and urate by $\mathrm{XO}$ in vivo [37]. As shown in Table 1, a previous study reports the anti-hyperglycemic effects of a water extract of $C$. tricuspidata leaves [15]. However, to the best of our knowledge, our present study is the first report on the process optimization of ethanolic extraction of phenolic phytochemical markers from C. tricuspidata leaves and the biological evaluation of the extracts and markers in terms of antioxidant and $\mathrm{XO}$ inhibitory activities.

Standard chemical profiling is crucial for optimization and quality control in natural source utilization. Chemical and chromatographic techniques may be used to characterize plant extracts. However, there has been no report on the standard profile for C. tricuspidata. Moreover, there is currently no other validated HPLC method reported for the simultaneous determination of chlorogenic acid, rutin, and kaempferol in the Moraceae family. Chlorogenic acid, rutin, and kaempferol are 
appropriate marker compound selections for the standardization of C. tricuspidata preparation and its anti-hyperuricemic/gout effects, on the basis of our results. Chlorogenic acid was also detected in the hot-water extract of $C$. tricuspidata fruit (0.18 $\pm 0.001 \%$; Figure 1$)$. Thus, our method can be used for the analysis and optimization of the C. tricuspidata fruit and leaf preparations.

\section{Experimental Section}

\subsection{Plant Material and Preparation of the Extract}

C. tricuspidata leaves and fruit were collected in May 2017 near Naju, in Jeonnam Province, Korea. A voucher specimen (MNUCSS-CT-01) was deposited in the College of Pharmacy, Mokpo National University (Muan-gun, Korea). The fruit and leaves were dried and extracted for the present study. The air-dried, powdered C. tricuspidata leaves and fruit (10 g) were extracted twice with 20-100\% ethanol $(100 \mathrm{~mL})$ at room temperature for 3 days. The $0 \%$ extract was prepared using hot-water extraction $\left(100{ }^{\circ} \mathrm{C} ; 4 \mathrm{~h}\right)$. After filtration, the resultant ethanol solution was evaporated, freeze-dried, and stored at $-50^{\circ} \mathrm{C}$. The crude extract was resuspended in ethanol and filtered using a $0.4 \mu \mathrm{m}$ membrane. All the samples were used for extraction optimization and in vitro experiments.

\subsection{Instrumentation and Chromatographic Conditions}

All analyses were performed on an Alliance 2695 HPLC system (Waters, Millford, MA, USA) equipped with a photodiode array detector. An Agilent Zorbax extended C18 analytical column (5 $\mu \mathrm{m}$, $150 \mathrm{~mm} \times 5 \mathrm{~mm}$ ) was used with a mobile phase consisting of a mixture of solvent A (acetonitrile) and solvent B (water containing $0.2 \%$ phosphoric acid). A gradient elution (from 10/90 to 100/0 v/v) at a flow rate of $0.8 \mathrm{~mL} / \mathrm{min}$ (Table 6) was employed. The column temperature was maintained at $25^{\circ} \mathrm{C}$, and the detection wavelength was $340 \mathrm{~nm}$. The solvent was filtered through a $0.22 \mu \mathrm{m}$ filter and was degassed. The sample injection volume was $10 \mu \mathrm{L}$.

Table 6. Analytical conditions of high-performance liquid chromatography (HPLC) for analysis of the three standards.

\begin{tabular}{|c|c|c|c|}
\hline Parameter & \multicolumn{3}{|c|}{ Condition } \\
\hline Column & \multicolumn{3}{|c|}{ Zorbax extended C18 (C18; $4.6 \mathrm{~mm} \times 150 \mathrm{~mm}, 5 \mu \mathrm{m})$} \\
\hline Flow rate & \multicolumn{3}{|c|}{$0.8 \mathrm{~mL} / \mathrm{min}$} \\
\hline Injection volume & \multicolumn{3}{|c|}{$10 \mu \mathrm{L}$} \\
\hline UV detection & \multicolumn{3}{|c|}{$340 \mathrm{~nm}$} \\
\hline Run time & \multicolumn{3}{|c|}{$24 \min$} \\
\hline \multirow{7}{*}{ Gradient } & Time (min) & $\% \mathrm{~A}^{1}$ & $\% \mathrm{~B}^{2}$ \\
\hline & 0 & 10 & 90 \\
\hline & 5 & 10 & 90 \\
\hline & 18 & 50 & 50 \\
\hline & 20 & 100 & 0 \\
\hline & 21 & 10 & 90 \\
\hline & 25 & 10 & 90 \\
\hline
\end{tabular}

${ }^{1}$ Acetonitrile; ${ }^{2} 0.2 \%$ phosphoric acid.

\subsection{Preparation of Standards and Sample Solutions}

\subsubsection{Standard Solutions}

Accurately weighed appropriate amounts of the reference compounds (chlorogenic acid, rutin and kaempferol) were mixed and dissolved in methanol in a $100 \mathrm{~mL}$ volumetric flask, to obtain a stock solution of $100 \mu \mathrm{g} / \mathrm{mL}$. The solutions were subsequently two-fold serially diluted to $3.125 \mu \mathrm{g} / \mathrm{mL}$. The reference compounds of analytical standard grade were purchased from Sigma-Aldrich Chemical Co. (St. Louis, MO, USA). 


\subsubsection{Sample Solutions}

The crude extract $(0.5 \mathrm{~g})$ was dissolved in methanol $(10 \mathrm{~mL})$. This sample was sonicated to expedite the dissolution of particles. Subsequently, $1 \mathrm{~mL}$ was transferred to a volumetric flask and diluted with $9 \mathrm{~mL}$ of mobile phase A to obtain a final solution with a known concentration of $25 \mathrm{mg} / \mathrm{mL}$.

\subsection{Method Validation}

The analytical method used for the quantification of chlorogenic acid, rutin and kaempferol in the ethanolic extract of $C$. tricuspidata leaves and fruit was validated in terms of specificity, linearity, sensitivity, accuracy, precision and recovery, as previously described $[38,39]$.

\subsubsection{Specificity}

Specificity is the ability of a method to discriminate between the study analytes and other constituents in the sample. The specificity of the HPLC method was demonstrated by the separation of analytes from other potential constituents, such as impurities, degradants, or excipients [40]. The resolution between the peaks corresponding to the main constituents found in the ethanolic extract of $C$. tricuspidata was determined by the analysis of chromatograms of the standard solution and the sample solution. This resolution was calculated using Waters Empower software (version 1, Waters, Milford, MA, USA).

\subsubsection{Linearity}

The linearity was analyzed using three calibration curves obtained using standard solutions at five different concentrations in the range of $6.25-100 \mu \mathrm{g} / \mathrm{mL}$ for chlorogenic acid, rutin, and kaempferol. The data for the peak area versus the drug concentration were treated with linear regression analysis using Excel software.

\subsubsection{Sensitivity}

The LOD was determined from the calibration curves of the chlorogenic acid, rutin, and kaempferol standards. The LOD was calculated as the SDR $\times 3 / \mathrm{S}$, where SDR was the standard deviation of the response and $S$ was the slope of the calibration curve. The LOQ was set to the lowest level of the calibration curves with acceptable precision and accuracy.

\subsubsection{Accuracy and Precision}

The accuracy and precision were evaluated using recovery assays carried out by adding known amounts of the standards to the sample, at three different levels $(12.5,25$ and $50 \mu \mathrm{g} / \mathrm{mL})$ of the initial concentration of the sample. Each solution was injected in triplicate within one day or three consecutive days. The intraday and interday accuracy were expressed as the observed concentration relative to the true concentration. The intraday and interday precisions were expressed as the RSD.

\subsubsection{Recovery}

Recovery was assessed by analyzing the peak areas using six determinations at three different levels, that is, $12.5,25$ and $50 \mu \mathrm{g} / \mathrm{mL}$. Variations were expressed as the percentage of the standard concentration and the RSD.

\subsubsection{Statistical Analysis}

Statistical analysis of the data was performed with Excel software. 


\subsection{Analysis of the Extract from C. tricuspidata Leaves}

The HPLC method developed herein was used to quantitatively determine the amounts of the three markers in five extracts from C. tricuspidata leaves and fruit.

\subsection{DPPH Free Radical Assay}

Antioxidant activities of the different extracts were determined by the DPPH radical scavenging method. DPPH radicals have an absorption maximum of $517 \mathrm{~nm}$, which disappears with reduction by an antioxidant compound. Ethanolic solution (1 mL) containing 1-20 mg of extract was added to a $0.4 \mathrm{mM}$ DPPH ethanolic solution $(1 \mathrm{~mL})$. The solution was mixed, and the reaction was allowed to proceed at room temperature in the dark for $10 \mathrm{~min}$. The absorbance at $517 \mathrm{~nm}$ was measured with a microplate reader (Perkin Elmer, Waltham, MA, USA). The radical scavenging activity was calculated as a percentage using the following equation:

$$
\text { DPPH radical scavenging activity }(\%)=\left[1-\left(\mathrm{A}_{\text {sample }} / \mathrm{A}_{\text {blank }}\right)\right] \times 100
$$

The DPPH free radical scavenging activities of samples were compared regarding their $\mathrm{IC}_{50}$ $(\mu \mathrm{g} / \mathrm{mL})$ values.

\subsection{Reducing Power}

The reducing power of the sample was determined according to a modified reducing power assay method. The sample $(0.1 \mathrm{~mL})$ was added to $0.2 \mathrm{M}$ sodium phosphate buffer $(0.5 \mathrm{~mL})$ with $1 \%$ potassium ferricyanide $(0.5 \mathrm{~mL})$, and incubated at $50{ }^{\circ} \mathrm{C}$ for $20 \mathrm{~min}$. Following incubation, $10 \%$ trichloroacetic acid solution $(0.5 \mathrm{~mL})$ was added to the reaction mixture, and it was centrifuged at $2000 \times g$ for $10 \mathrm{~min}$. The supernatant was mixed with distilled water $(0.5 \mathrm{~mL})$ and a $0.1 \%$ iron (III) chloride solution $(0.1 \mathrm{~mL})$, and the absorbance at $700 \mathrm{~nm}$ of the resulting solution was measured. Reducing powers of samples were expressed as vitamin $C$ equivalents.

\subsection{Determination of Total Phenolic Content}

The total phenolic content was determined using the Folin-Ciocalteu assay. An aqueous solution $(1 \mathrm{~mL})$ containing $5 \mathrm{mg}$ of the freeze-dried extract or standard was mixed with $1 \mathrm{~mL}$ of $2 \%$ sodium carbonate solution and $1 \mathrm{~mL}$ of $10 \%$ Folin-Ciocalteu phenol reagent. After $10 \mathrm{~min}$, the absorbance was measured at $750 \mathrm{~nm}$ using a microplate reader (Perkin Elmer). The measurement was compared to a calibration curve of gallic acid. The results were expressed as milligrams of gallic acid equivalents per gram of the sample.

\subsection{Determination of Total Flavonoids}

The total flavonoid content was determined by a previously reported colorimetric method. Briefly, a $0.5 \mathrm{~mL}$ aliquot of the sample solution was mixed with distilled water $(2 \mathrm{~mL})$ and subsequently with $5 \% \mathrm{NaNO}_{2}$ solution $(0.15 \mathrm{~mL})$. After incubation for $5 \mathrm{~min}$, a $0.15 \mathrm{~mL}$ aliquot of $10 \% \mathrm{AlCl}_{3}$ solution was added to the mixture, and after $5 \mathrm{~min}, 4 \% \mathrm{NaOH}$ solution $(2 \mathrm{~mL})$ was added to the mixture. Water was added to the sample to bring the final volume to $5 \mathrm{~mL}$, and the mixture was thoroughly mixed and allowed to stand for $15 \mathrm{~min}$. The absorbance of the resultant mixture was measured at $415 \mathrm{~nm}$. Then, the total flavonoid content was calculated as quercetin (QCT) equivalents (mg QCT/g extract) by reference to a standard curve $\left(r^{2}=0.999\right)$.

\subsection{Determination of In Vitro Xanthine Oxidase (XO) Inhibitory Activity}

$\mathrm{XO}$ inhibitory activity was measured by monitoring uric acid formation in a $\mathrm{XO}$ system. The assay system consisted of $0.6 \mathrm{~mL}$ of phosphate buffer (100 mM; pH 7.4), $0.1 \mathrm{~mL}$ of the sample, $0.1 \mathrm{~mL}$ of $\mathrm{XO}(0.2 \mathrm{U} / \mathrm{mL})$, and $0.2 \mathrm{~mL}$ of xanthine $(1 \mathrm{mM}$; dissolved in $0.1 \mathrm{M} \mathrm{NaOH})$. The reaction was initiated 
by adding the enzyme with or without inhibitors, and the change in absorbance after $15 \mathrm{~min}$ of the mixture at $290 \mathrm{~nm}$ was measured against a reagent blank. A $0.2 \mathrm{~mL}$ aliquot of $1 \mathrm{M} \mathrm{HCl}$ was used to stop the enzymatic reaction. ALP was used as a positive control.

\section{Conclusions}

In the present study, ethanolic extracts of C. tricuspidata leaves were successfully prepared with varying ethanol contents and evaluated for their chemical profiles and biological activities. The $80 \%$ ethanolic extract was found to have the highest antioxidant activity and phenolic content, while the $100 \%$ ethanolic extract had the highest number of total flavonoids and highest XO inhibitory activity. The validated HPLC method was developed and applied to confirm that chlorogenic acid, rutin, and kaempferol were present in C. tricuspidata leaf extracts. These findings led us to suggest that the observed antioxidant and anti-hyperuricemic/gout effects of $C$. tricuspidata extract were attributed, at least in part, to the marker compounds. To the best of our knowledge, this is the first report on a validated analytical method for the standardization and optimization of biological properties of $C$. tricuspidata preparations. Further investigation is warranted to confirm the in vivo pharmacological activity of $C$. tricuspidata extract and its three constituents and to assess the safe use of the plant, which could lead to its potential development as an effective antioxidant and anti-hyperuricemic/gout agent.

Acknowledgments: This work was supported by the Korea Institute of Planning and Evaluation for Technology in Food, Agriculture, Forestry and Fisheries (IPET) through the Agri-Bioindustry Technology Development Program, funded by Ministry of Agriculture, Food and Rural Affairs (MAFRA; 316007-5).

Author Contributions: Sung Hwan Ki, In-Soo Yoon, and Seung-Sik Cho conceived and designed the experiments. Seung-Hui Song and Seung-Sik Cho performed the experiments and analyzed the data. Seung-Hui Song, Sung Hwan Ki, In-Soo Yoon, and Seung-Sik Cho wrote the manuscript. Dae-Hun Park, Hong-Seop Moon, and Chang-Dai Lee statistically analyzed the data.

Conflicts of Interest: The authors declare no conflict of interest.

\section{References}

1. Chang, S.H.; Jung, E.J.; Lim, D.G.; Oyungerel, B.; Lim, K.I.; Her, E.; Choi, W.S.; Jun, M.H.; Choi, K.D.; Han, D.J. Anti-inflammatory action of Cudrania tricuspidata on spleen cell and Tymphocyte proliferation. J. Pharm. Pharmacol. 2008, 60, 1221-1226. [CrossRef] [PubMed]

2. Park, K.H.; Park, Y.-D.; Han, J.-M.; Im, K.-R.; Lee, B.W.; Jeong, I.Y.; Jeong, T.-S.; Lee, W.S. Anti-atherosclerotic and anti-inflammatory activities of catecholic xanthones and flavonoids isolated from Cudrania tricuspidata. Bioorg. Med. Chem. Lett. 2006, 16, 5580-5583. [CrossRef] [PubMed]

3. Jeong, G.-S.; Lee, D.-S.; Kim, Y.-C. Cudratricusxanthone A from Cudrania tricuspidata suppresses pro-inflammatory mediators through expression of anti-inflammatory heme oxygenase-1 in RAW264.7 macrophages. Int. Immunopharmacol. 2009, 9, 241-246. [CrossRef] [PubMed]

4. Lee, Y.J.; Kim, S.; Lee, S.J.; Ham, I.; Whang, W.K. Antioxidant activities of new flavonoids from Cudrania tricuspidata root bark. Arch. Pharm. Res. 2009, 32, 195-200. [CrossRef] [PubMed]

5. Kwon, J.; Hiep, N.T.; Kim, D.-W.; Hong, S.; Guo, Y.; Hwang, B.Y.; Lee, H.J.; Mar, W.; Lee, D. Chemical constituents isolated from the root bark of Cudrania tricuspidata and their potential neuroprotective effects. J. Nat. Prod. 2016, 79, 1938-1951. [CrossRef] [PubMed]

6. Tian, Y.-H.; Kim, H.-C.; Cui, J.-M.; Kim, Y.-C. Hepatoprotective constituents of Cudrania tricuspidata. Arch. Pharm. Res. 2005, 28, 44-48. [CrossRef] [PubMed]

7. Lee, B.W.; Lee, J.H.; Lee, S.-T.; Lee, H.S.; Lee, W.S.; Jeong, T.-S.; Park, K.H. Antioxidant and cytotoxic activities of xanthones from Cudrania tricuspidata. Bioorg. Med. Chem. Lett. 2005, 15, 5548-5552. [CrossRef] [PubMed]

8. Hiep, N.T.; Kwon, J.; Kim, D.-W.; Hwang, B.Y.; Lee, H.-J.; Mar, W.; Lee, D. Isoflavones with neuroprotective activities from fruits of Cudrania tricuspidata. Phytochemistry 2015, 111, 141-148. [CrossRef] [PubMed]

9. Lee, H.; Ha, H.; Lee, J.K.; Seo, C.S.; Lee, N.H.; Jung, D.Y.; Park, S.J.; Shin, H.K. The fruits of Cudrania tricuspidata suppress development of atopic dermatitis in NC/Nga mice. Phytother. Res. 2012, 26, 594-599. [CrossRef] [PubMed] 
10. Han, X.H.; Hong, S.S.; Jin, Q.; Li, D.; Kim, H.-K.; Lee, J.; Kwon, S.H.; Lee, D.; Lee, C.-K.; Lee, M.K.; et al. Prenylated and benzylated flavonoids from the fruits of Cudrania tricuspidata. J. Nat. Prod. 2008, 72, 164-167. [CrossRef] [PubMed]

11. Jo, Y.H.; Kim, S.B.; Liu, Q.; Do, S.-G.; Hwang, B.Y.; Lee, M.K. Comparison of pancreatic lipase inhibitory isoflavonoids from unripe and ripe fruits of Cudrania tricuspidata. PLoS ONE 2017, 12, e0172069. [CrossRef] [PubMed]

12. Lee, T.; Kwon, J.; Lee, D.; Mar, W. Effects of Cudrania tricuspidata fruit extract and its active compound, $5,7,3^{\prime}, 4^{\prime}$-tetrahydroxy-6,8-diprenylisoflavone, on the high-affinity IgE receptor-mediated activation of Syk in mast cells. J. Agric. Food Chem. 2015, 63, 5459-5467. [CrossRef] [PubMed]

13. Han, X.H.; Hong, S.S.; Hwang, J.S.; Jeong, S.H.; Hwang, J.H.; Lee, M.H.; Lee, M.K.; Lee, D.; Ro, J.S.; Hwang, B.Y. Monoamine oxidase inhibitory constituents from the fruits of Cudrania tricuspidata. Arch. Pharm. Res. 2005, 28, 1324-1327. [CrossRef] [PubMed]

14. Jo, Y.H.; Choi, K.-M.; Liu, Q.; Kim, S.B.; Ji, H.-J.; Kim, M.; Shin, S.-K.; Do, S.-G.; Shin, E.; Jung, G. Anti-obesity effect of 6,8-diprenylgenistein, an isoflavonoid of Cudrania tricuspidata fruits in high-fat diet-induced obese mice. Nutrients 2015, 7, 10480-10490. [CrossRef] [PubMed]

15. Kim, O.-K.; Nam, D.-E.; Jun, W.; Lee, J. Cudrania tricuspidata water extract improved obesity-induced hepatic insulin resistance in $\mathrm{db} / \mathrm{db}$ mice by suppressing ER stress and inflammation. Food Nutr. Res. 2015, 59. [CrossRef] [PubMed]

16. Seo, J.-H.; Kim, J.-E.; Shim, J.-H.; Yoon, G.; Bang, M.; Bae, C.-S.; Lee, K.-J.; Park, D.-H.; Cho, S.-S. HPLC analysis, optimization of extraction conditions and biological evaluation of Corylopsis coreana Uyeki Flos. Molecules 2016, 21, 94. [CrossRef] [PubMed]

17. Shi, H.; Shi, A.; Dong, L.; Lu, X.; Wang, Y.; Zhao, J.; Dai, F.; Guo, X. Chlorogenic acid protects against liver fibrosis in vivo and in vitro through inhibition of oxidative stress. Clin. Nutr. 2016, 35, 1366-1373. [CrossRef] [PubMed]

18. Tatsimo, S.J.N.; de Dieu Tamokou, J.; Havyarimana, L.; Csupor, D.; Forgo, P.; Hohmann, J.; Kuiate, J.-R.; Tane, P. Antimicrobial and antioxidant activity of kaempferol rhamnoside derivatives from Bryophyllum pinnatum. BMC Res. Notes 2012, 5, 158. [CrossRef] [PubMed]

19. Boyle, S.; Dobson, V.; Duthie, S.; Hinselwood, D. Bioavailiability and efficiency of rutin as an antioxidant: A human supplementation study. Eur. J. Clin. Nutr. 2000, 54, 774-782. [CrossRef] [PubMed]

20. Yoon, I.S.; Park, D.H.; Ki, S.H.; Cho, S.S. Effects of extracts from Corylopsis coreana Uyeki (Hamamelidaceae) flos on xanthine oxidase activity and hyperuricemia. J. Pharm. Pharmacol. 2016, 68, 1597-1603. [CrossRef] [PubMed]

21. Citraro, R.; Navarra, M.; Leo, A.; Donato Di Paola, E.; Santangelo, E.; Lippiello, P.; Aiello, R.; Russo, E.; De Sarro, G. The anticonvulsant activity of a flavonoid-rich extract from orange juice involves both NMDA and GABA-benzodiazepine receptor complexes. Molecules 2016, 21, 1261. [CrossRef] [PubMed]

22. Huang, M.; Deng, S.; Han, Q.; Zhao, P.; Zhou, Q.; Zheng, S.; Ma, X.; Xu, C.; Yang, J.; Yang, X.; et al. Hypoglycemic activity and the potential mechanism of the flavonoid rich extract from Sophora tonkinensis Gagnep. in KK-Ay mice. Front. Pharmacol. 2016, 7, 288. [CrossRef] [PubMed]

23. Peng, K.-Z.; Yang, X.; Zhou, H.-L.; Pan, S.-X. Safety evaluation, in vitro and in vivo antioxidant activity of the flavonoid-rich extract from Maydis stigma. Molecules 2015, 20, 22102-22112. [CrossRef] [PubMed]

24. Gajaria, T.K.; Patel, D.K.; Devkar, R.V.; Ramachandran, A. Flavonoid rich extract of Murraya koenigii alleviates in-vitro LDL oxidation and oxidized LDL induced apoptosis in raw 264.7 Murine macrophage cells. J. Food Sci. Technol. 2015, 52, 3367-3375. [CrossRef] [PubMed]

25. Liu, M.; Xu, Y.; Han, X.; Liang, C.; Yin, L.; Xu, L.; Qi, Y.; Zhao, Y.; Peng, J.; Sun, C. Potent effects of flavonoid-rich extract from Rosa laevigata Michx fruit against hydrogen peroxide-induced damage in PC12 cells via attenuation of oxidative stress, inflammation and apoptosis. Molecules 2014, 19, 11816-11832. [CrossRef] [PubMed]

26. Yoon, I.-S.; Park, D.-H.; Bae, M.-S.; Oh, D.-S.; Kwon, N.-H.; Kim, J.-E.; Choi, C.-Y.; Cho, S.-S. In vitro and in vivo studies on Quercus acuta Thunb. (Fagaceae) extract: Active constituents, serum uric acid suppression, and xanthine oxidase inhibitory activity. Evid. Based Complement. Altern. Med. 2017, 2017, 4097195. [CrossRef] [PubMed] 
27. Yoon, I.S.; Park, D.H.; Kim, J.E.; Yoo, J.C.; Bae, M.S.; Oh, D.S.; Shim, J.H.; Choi, C.Y.; An, K.W.; Kim, E.I.; et al. Identification of the biologically active constituents of Camellia japonica leaf and anti-hyperuricemic effect in vitro and in vivo. Int. J. Mol. Med. 2017, 39, 1613-1620. [CrossRef] [PubMed]

28. Ganeshpurkar, A.; Saluja, A.K. The pharmacological potential of rutin. Saudi Pharm. J. 2017, 25, $149-164$. [CrossRef] [PubMed]

29. Chen, Y.-S.; Hu, Q.-H.; Zhang, X.; Zhu, Q.; Kong, L.-D. Beneficial effect of rutin on oxonate-induced hyperuricemia and renal dysfunction in mice. Pharmacology 2013, 92, 75-83. [CrossRef] [PubMed]

30. Zhu, J.X.; Wang, Y.; Kong, L.D.; Yang, C.; Zhang, X. Effects of Biota orientalis extract and its flavonoid constituents, quercetin and rutin on serum uric acid levels in oxonate-induced mice and xanthine dehydrogenase and xanthine oxidase activities in mouse liver. J. Ethnopharmacol. 2004, 93, 133-140. [CrossRef] [PubMed]

31. Zatorski, H.; Sałaga, M.; Zielińska, M.; Piechota-Polańczyk, A.; Owczarek, K.; Kordek, R.; Lewandowska, U.; Chen, C.; Fichna, J. Experimental colitis in mice is attenuated by topical administration of chlorogenic acid. Naunyn Schmiedebergs Arch. Pharmacol. 2015, 388, 643-651. [CrossRef] [PubMed]

32. Meng, Z.-Q.; Tang, Z.-H.; Yan, Y.-X.; Guo, C.-R.; Cao, L.; Ding, G.; Huang, W.-Z.; Wang, Z.-Z.; Wang, K.D.; Xiao, W.; et al. Study on the anti-gout activity of Chlorogenic acid: Improvement on hyperuricemia and gouty inflammation. Am. J. Chin. Med. 2014, 42, 1471-1483. [CrossRef] [PubMed]

33. Hwang, S.J.; Kim, Y.-W.; Park, Y.; Lee, H.-J.; Kim, K.-W. Anti-inflammatory effects of chlorogenic acid in lipopolysaccharide-stimulated RAW 264.7 cells. Inflamm. Res. 2014, 63, 81-90. [CrossRef] [PubMed]

34. Kim, H.-R.; Lee, D.-M.; Lee, S.-H.; Seong, A.-R.; Gin, D.-W.; Hwang, J.-A.; Park, J.-H. Chlorogenic acid suppresses pulmonary eosinophilia, IgE production, and Th2-type cytokine production in an ovalbumin-induced allergic asthma: Activation of STAT-6 and JNK is inhibited by chlorogenic acid. Int. Immunopharmacol. 2010, 10, 1242-1248. [CrossRef] [PubMed]

35. Wang, Y.; Zhang, G.; Pan, J.; Gong, D. Novel insights into the inhibitory mechanism of kaempferol on xanthine oxidase. J. Agric. Food Chem. 2015, 63, 526-534. [CrossRef] [PubMed]

36. Goel, R.; Pandey, V.; Dwivedi, S.; Rao, Y. Antiinflammatory and antiulcer effects of kaempferol, a flavone, isolated from Rhamnus procumbens. Indian J. Exp. Biol. 1988, 26, 121-124. [PubMed]

37. Nagao, A.; Seki, M.; Kobayashi, H. Inhibition of xanthine oxidase by flavonoids. Biosci. Biotechnol. Biochem. 1999, 63, 1787-1790. [CrossRef] [PubMed]

38. Vats, P.; Verma, S.M.; Monif, T. Novel LC-MS/MS method for estimation of niacin with negligible matrix effect and its application to the BE study. J. Pharm. Investig. 2017, 47, 241-248. [CrossRef]

39. Adib, N.A.M.; Mandal, U.K.; Mohamed, F.; Chatterjee, B. Fast and simple gas chromatographic method for simultaneous estimation of camphor, menthol and methyl salicylate in analgesic ointment: Application in stability study. J. Pharm. Investig. 2017, 47, 275-285. [CrossRef]

40. Landim, L.P.; Feitoza, G.S.; da Costa, J.G. Development and validation of a HPLC method for the quantification of three flavonoids in a crude extract of Dimorphandra gardneriana. Rev. Bras. Farmacogn. 2013, 23, 58-64. [CrossRef]

Sample Availability: Samples of the compounds are available from the authors.

(C) 2017 by the authors. Licensee MDPI, Basel, Switzerland. This article is an open access article distributed under the terms and conditions of the Creative Commons Attribution (CC BY) license (http://creativecommons.org/licenses/by/4.0/). 